\title{
In memoriam Michel Cullin (1944-2020)
}

\author{
Jacques Lajarrige
}

\section{OpenEdition}

Journals

Édition électronique

URL : https://journals.openedition.org/austriaca/1491

DOI : 10.4000/austriaca. 1491

ISSN : 2729-0603

\section{Éditeur}

Presses universitaires de Rouen et du Havre

\section{Édition imprimée}

Date de publication : 1 juin 2020

Pagination : 229-230

ISBN : 979-10-240-1492-0

ISSN : 0396-4590

\section{Référence électronique}

Jacques Lajarrige, «In memoriam Michel Cullin (1944-2020) », Austriaca [En ligne], 90 | 2020, mis en ligne le 01 juin 2020, consulté le 29 septembre 2022. URL : http://journals.openedition.org/austriaca/ 1491 ; DOI : https://doi.org/10.4000/austriaca.1491

Ce document a été généré automatiquement le 29 septembre 2022

Tous droits réservés 


\title{
In memoriam Michel Cullin (1944-2020)
}

\author{
Jacques Lajarrige
}

1 C'est avec tristesse que nous avons appris le décès de Michel Cullin, survenu à Vienne le 3 mars 2020. Notre revue perd ainsi l'un de ses membres fondateurs et plus anciens collaborateurs.

2 Né le 17 septembre 1944 à Paris, Michel Cullin aura été, tout au long de sa vie et dans les différentes fonctions qu'il occupa, tant dans le domaine universitaire que diplomatique, un remarquable observateur et un infatigable acteur des relations francoautrichiennes, mais aussi franco-allemandes.

3 Après des études de sciences politiques et d'allemand (1962-1965) à Paris, Michel Cullin avait vite trouvé le chemin de la capitale autrichienne, où il fut d'abord assistant de français au Theresianum (1966-1967), avant de devenir lecteur à l'université de Vienne, puis de rejoindre le Geschwister-Scholl-Institut de l'université Ludwig-Maximilian de Munich (1969-1971). Expériences fondatrices de l'étranger qui contribueront grandement à décider de l'orientation ultérieure de son parcours de chercheur et de spécialiste de l'Autriche, comme en témoigne le manuel précurseur co-écrit avec son ami et maître Felix Kreissler, L'Autriche contemporaine (Paris, Armand Colin, 1972), qui participa non seulement de l'évolution des études germaniques en France, mais, de manière plus décisive encore, installa l'Autriche comme sujet d'étude à part entière de cette branche nouvelle qui s'imposera peu à peu sous la dénomination de « civilisation ».

Devenu assistant, puis maître-assistant et maître de conférences de civilisation autrichienne (1971-1982) à l'université d'Orléans, il contribua à l'essor des études autrichiennes en France, dont sa thèse de doctorat Les théories de la nation autrichienne entre 1934 et 1938, entreprise sous la direction de Pierre Bertaux et soutenue en 1978 devant l'université Paris 3, est un bel exemple. On peut en dire autant des articles publiés dans Austriaca qui dessinent pareillement le contour de ses intérêts historiques variés pour les différents aspects de la culture politique autrichienne, allant des orientations antisémites du catholicisme autrichien à la résistance catholique avant et 
après l'Anschluss ou aux débats à l'intérieur de la gauche autrichienne pendant la Première et la Deuxième République.

5 C'est ensuite largement en dehors du cadre universitaire qu'il continuera d'œuvrer. D'abord en retournant à Vienne, où il prend la direction de l'Institut français, fonction qu'il occupa de 1982 à 1986. Il est ensuite et jusqu'en 1991 professeur associé à l'université de Vienne, tout en répondant aux invitations de plusieurs universités allemandes (Heidelberg, Leipzig et Iéna) et en commentant pour la presse française (Libération, Le Monde diplomatique, La Croix) l'actualité politique autrichienne.

6 C'est vers l'Allemagne que le conduisirent ensuite ses nouvelles responsabilités d'attaché de coopération universitaire à l'Ambassade de France en Allemagne (1991-1995). S'ensuivit un bref retour dans le giron universitaire comme maitre de conférences à l'université de Nice (1999 à 2003), autre lieu historiquement important des études autrichiennes en France. Mais plus à son aise dans l'action diplomatique et les échanges internationaux que dans l'université française, Michel Cullin retrouva comme secrétaire général adjoint de l'office franco-allemand pour la jeunesse (1999-2003), aux côtés de Babette Nieder, des fonctions à la mesure de ses intérêts et compétences dans ce domaine, orientant les rencontres entre jeunes Français et Allemands vers le travail de mémoire et développant des projets trinationaux avec les pays d'Europe du Sud-Est et ceux d'Europe centrale. Cette même volonté guidera de même son action et son enseignement à la Diplomatische Akademie de Vienne, où il exerça jusqu'en 2017.

7 Humaniste, citoyen engagé, militant politique, homme de réseaux, Michel Cullin fut également très actif au sein de la Fédération des Français de l'étranger du Parti socialiste (FFE-PS), créée en 1983 dans le but de relayer et de diffuser les idées et propositions du Parti socialiste auprès des ressortissants français établis à l'étranger.

Parmi ses engagements forts, il faut également mentionner à partir de 2008 son action en tant que représentant de la France au conseil international de l'association autrichienne du Service autrichien à l'étranger (Verein Österreichischer Auslandsdienst), qui offre aux jeunes Autrichiens désireux d'accomplir un service civil de nombreuses possibilités de collaborations internationales et d'accueil comme volontaires auprès de mémoriaux et institutions françaises comme le Centre de la mémoire d'Oradour-surGlane ou la Fondation pour la mémoire de la déportation.

9 Nos pensées vont à sa famille et à ses proches à qui nous adressons nos plus sincères condoléances. 